\title{
Carbon Monoxide Concentration Monitoring in Akure-A Comparison between Urban and Rural Environment
}

\author{
Ifeoluwa Adebowale Balogun ${ }^{*}$, Ahmed Adedoyin Balogun', Jimmy Adegoke ${ }^{2}$ \\ ${ }^{1}$ Department of Meteorology, Federal University of Technology, Akure, Nigeria \\ ${ }^{2}$ Department of Geosciences, University of Missouri-Kansas City, Missouri, USA \\ Email: ${ }^{\text {iabalogun@futa.edu.ng }}$
}

Received 12 June 2013; revised 3 January 2014; accepted 2 February 2014

Copyright (C) 2014 by authors and Scientific Research Publishing Inc.

This work is licensed under the Creative Commons Attribution International License (CC BY).

http://creativecommons.org/licenses/by/4.0/

\section{(c) (i) Open Access}

\begin{abstract}
Air pollution has been identified to be one major problem associated with urbanisation, particularly in developing countries. In this regard, this paper utilizes data from a year-long experiment of simultaneous measurements to examine and compare the variations of carbon monoxide concentrations, a major air pollutant at urban and rural site in Akure, a medium-sized tropical city in south western Nigeria. The comparison was done to assess the urban influence on the air pollutant. CO concentrations at the urban centre have been identified to exhibit distinct diurnal and day-ofweek variations with respect to traffic rush hours. It is also observed that the concentrations at the urban centre were 2 - 3 times higher than that of the rural site which exhibited a consistent cyclic diurnal pattern throughout the week. Results further identified the major cause of CO concentration in the urban centre to be vehicular as consistent increase of the air pollutant from 08:00 to 16:00 during the weekdays is found to be associated with "school runs and rush hours" and also rises through the midnight hours on days linked with social events, particularly Saturdays. In relation to human health and World Health Organisation (WHO) guidelines, results showed that $\mathrm{CO}$ concentrations at the urban centre exceeded the WHO 8-hour average recommendation during daytime throughout the weekdays.
\end{abstract}

\section{Keywords}

Carbon Monoxide; Urban; Rural; World Health Organisation

\section{Introduction}

World population is forecast to reach 9 billion by 2050, with almost all the growth in developing countries [1].

\footnotetext{
"Corresponding author.
}

How to cite this paper: Balogun, I.A., Balogun, A.A. and Adegoke, J. (2014) Carbon Monoxide Concentration Monitoring in Akure-A Comparison between Urban and Rural Environment. Journal of Environmental Protection, 5, $266-273$. 
Africa is the fastest urbanizing continent in the world and it has been reported that Africa should prepare for a total population increase of about 60 per cent between 2010 and 2050 [2]. This rapid growth of urban areas is among the most important anthropogenic impacts on the environment, and it has a profound impact on both the urban climate and air quality. A major problem that generally follows rapid urbanization, especially in developing countries, is a deterioration of air quality with adverse effects for human health due to increased emissions from traffic. This is especially true in the developing countries, mainly due to the high proportion of old, poorly maintained vehicles, the abundance of two-stroke motorcycles and the poor fuel quality [3] [4]. One of the main sources of atmospheric pollution in the urban environment is motor vehicle emission [5]. It was concluded that cities in Sub-Saharan Africa are among the most polluted in the world and in great need of air quality management measures in their development at the Better Air Quality Sub-Saharan Africa regional conference in Nairobi 2006 [6]. However, relatively little is known about urban air quality status in developing countries as systematic measurement and monitoring of urban environmental health risks connected to air pollution has received very limited attention [7]. This knowledge gap in the air quality of urban areas of sub-Saharan Africa may consequently restrict adaptation to the extreme urbanization rate [2].

Carbon monoxide is a tasteless, colorless and odorless gas mainly produced from incomplete combustion. It is a poisonous gas that when inhaled, combines with haemoglobin to form carboxyhaemoglobin, thereby preventing absorption of oxygen and resulting in asphyxiation. Considered as a criterion of air pollutant, CO is an important component in urban and indoor air pollution because of its short-term harmful health effects. Transportation accounts for $90 \%$ of its total emissions [8]. The highest CO concentrations occur in close proximity to motor vehicles emissions [9] [10]. Health based guidelines for maximum ambient CO-levels are: 86 ppm for 15 min, $52 \mathrm{ppm}$ for $30 \mathrm{~min}, 26 \mathrm{ppm}$ for $1 \mathrm{~h}$ and $9 \mathrm{ppm}$ for $8 \mathrm{~h}$ exposuree [11]. CO is also closely linked to the chemical production and destruction of ozone, which is a greenhouse gas and major pollutant harmful to human health and plants. Recent studies have shown that together with other reactive gases, CO emissions indirectly affect changes in radiative forcing [12]. CO can thus be considered to be an indirect greenhouse gas on the basis of its effect on the lifetime of other greenhouse gases.

Carbon monoxide (CO) concentration at various forms has been investigated particularly in the Mid-latitudes/European countries. Studies have indicated that city dwellers are exposed to the highest levels of CO during commuting compared to other situations [13] [14]. Several researches involved measuring pollution near the streets [15]-[18] and/or employing personal monitoring devices [14] [19] have been carried out in several cities, but limited work has been performed in the tropics and mostly in the developing world [20]. Amongst the few work done in West Africa is the work done [21] on carbon monoxide in Ouagadougou, Burkina Faso.

This paper reports results from a year-long measurement campaign. It is probably the first of its kind for the city, investigating the variation of $\mathrm{CO}$ concentrations at a rural and urban site in a rapidly growing medium size hot humid tropical city, Akure in southwestern Nigeria.

\section{The Study City}

Akure, the capital city of Ondo State, Nigeria is located on latitude $7.25^{\circ} \mathrm{N}$ and longitude $5.20^{\circ} \mathrm{E}$ (Figure 1). The rapid growth of the city, particularly within the last few decades, has made it one of the fastest growing metropolitan cities in the South Western Nigeria. Its population has more than tripled from 157,947 in 1990 to $\sim 500,000$ in 2006 [22]. The city became an administrative and economic seat to Akure South Local Government Authority, and Ondo State with the latter's creation in 1976 from the old Western State. Since then, the city has witnessed immense growth in the size of built-up areas, number of inhabitants, transportation, and commercial activities. The rapid growth of Akure has made it one of the fastest growing metropolitan cities in the South Western Nigeria. Within the last three decades, subsequent changes in the land-atmosphere energy balance relationships have occurred alongside traffic related air quality degradation over the city [23]. The city is one of the Millennium Cities Initiative Project of the Columbian University \& Columbian national investment working with Millennium Developmental Goals (MDG) support team of the United Nations Development Program [24].

\section{Data Description and Methodology}

A yearlong carbon monoxide measurement campaign was conducted between March 2009 - February 2010 in the central business district of the city and a rural site located about $15 \mathrm{~km}$ east on the outskirt of the city along the seldom used old airport. The sites are classified as local climate zones 2 (compact midrise) and local climate 


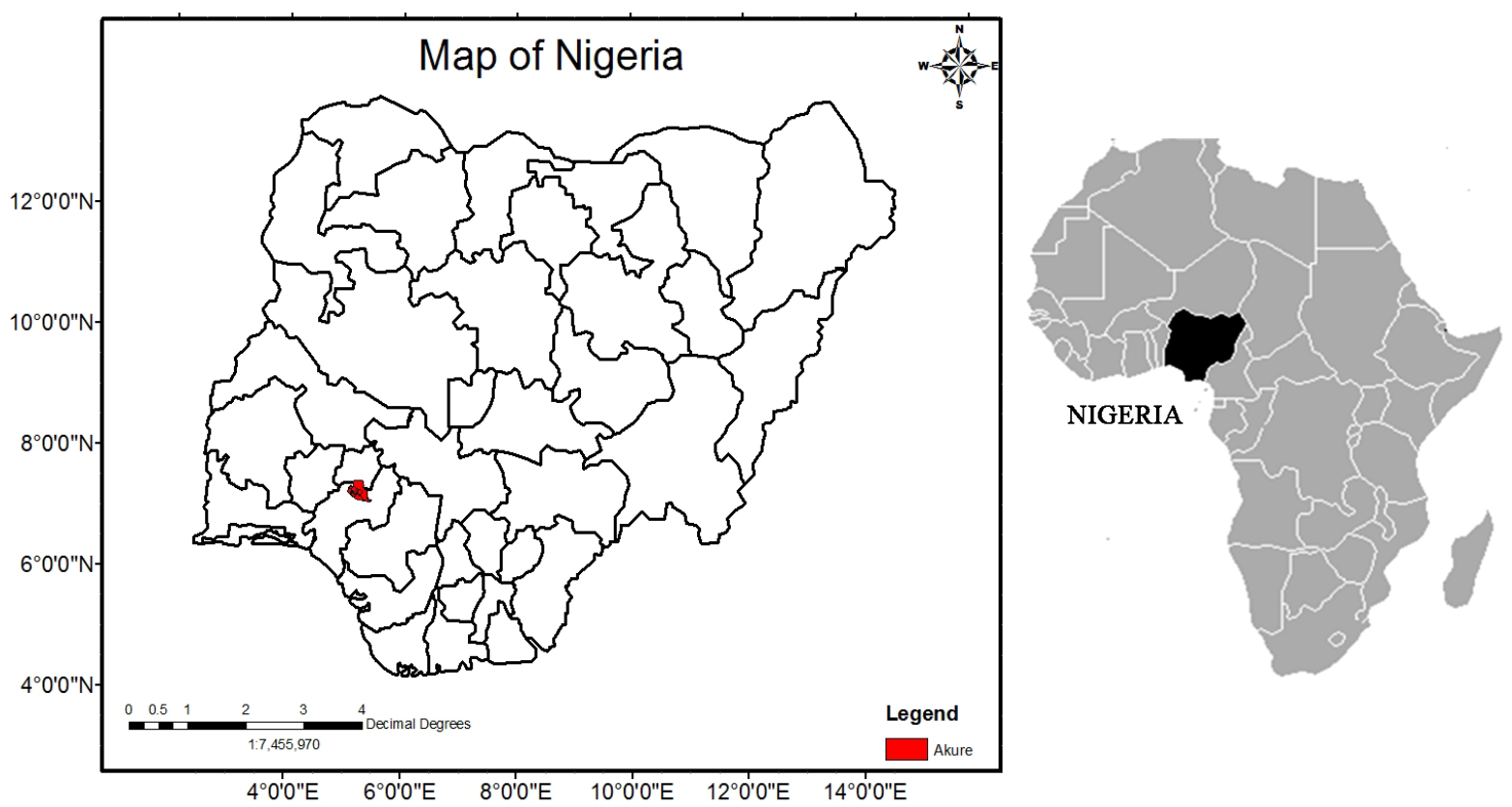

Figure 1. Map showing position of Akure (red) in Nigeria (left) and Nigeria in Africa (right).

zone 10 (sparsely built) respectively [25]. CO measurements were made using the Lascar EL-USB-CO portable data loggers with a sampling frequency of 30 seconds, accuracy of \pm 6 , resolution of 0.5 and a measuring range of 0 - 1000 ppm that were mounted on lamp posts above head height $(3 \mathrm{~m})$. Required time averages were then computed from the raw data and analysed. Statistical approach was adopted in analyzing the CO data in relation to the World Health Organisation (WHO) standard recommendations of $15 \mathrm{~min}, 30 \mathrm{~min}, 1 \mathrm{hr}$, and 8 hr averages.

\section{Results and Discussion}

\subsection{Observed Characteristics of Carbon Monoxide over Akure}

The average diurnal variation of CO concentrations over the urban and rural sites for (a) 1 minute, (b) 30 minute, (c) 1 hour and (d) 8 hour mean for the 1-year under consideration are presented in Figure 2. CO concentrations at the city centre in Akure exhibited distinct diurnal variations with two main peak periods, while the rural site exhibited a consistent similar cyclic diurnal pattern throughout. It is shown that atmospheric contents of carbon monoxide concentrations at the urban site exceed that of the rural site for all the World Health Organisation WHO time criteria. However, it is for the 8-hour average only that the WHO health based guidelines of 9 ppm for maximum ambient CO-levels exposure were strongly exceeded at the urban site. The 8-hour average CO characteristics of the urban site for weekdays and monthly averages are further evaluated and the results were presented in Figure 3. A rising trend of CO concentration from early hours with the average period of maximum CO concentration around 1600 is observed for the weekdays and monthly evaluations. In all the months, the 8 hour WHO recommendation was exceeded mostly from around 1200. It was evident that Fridays are the highest concentrated days while Sundays recorded the least. This is premised on the fact that the Muslim's Jumaat service holds on Friday afternoons at the central mosque located at the city centre. Apart from this, other social factors are wedding engagement ceremonies that have been identified to usually take place on Fridays, the eve of the wedding day; the typical high volume of commuters travelling for the weekend and increased shopping activities attributed to the weekend. The traditional African social life also appends its signature on the level of CO concentration observed in its pattern on Saturdays. It is usually a day that has been dedicated to events which usually attract late afternoon/night parties, family fun time and associated late week shopping as Sundays attracts lesser market activities. As shown in Figure 3(b) for weekdays 8-hr mean, Saturdays exhibits a consistent increase in CO concentration from 16:00 through the midnight hours which makes it distinct from every other day. High volume of traffic in the city by the merry-makers increased the concentration level of the pollutants in the city. 

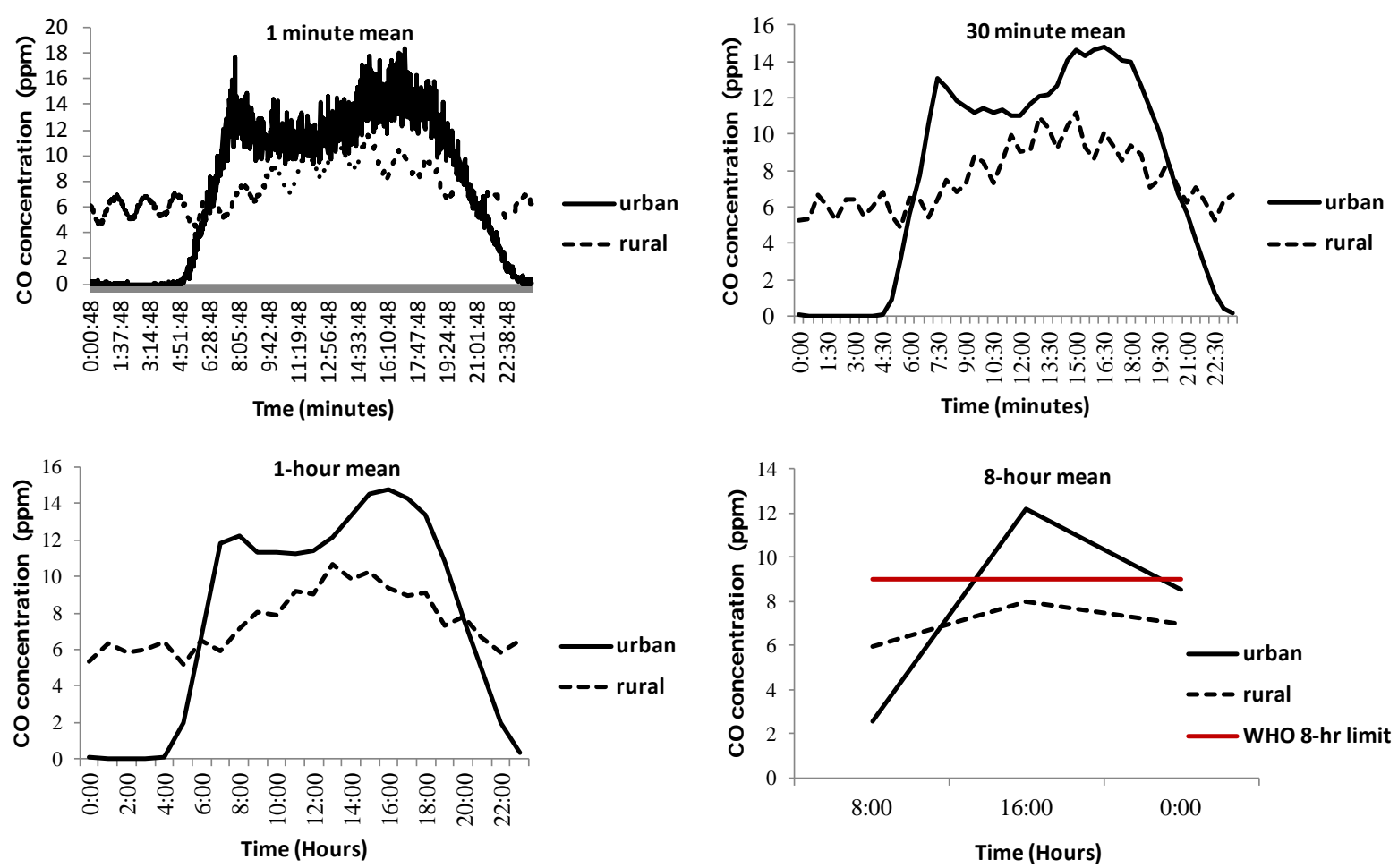

Figure 2. Diurnal variation of urban CO concentrations averaged over urban and rural sites for 1 minute, 30 minute, 1 hour and 8 hour average from March, 2009-February, 2010.

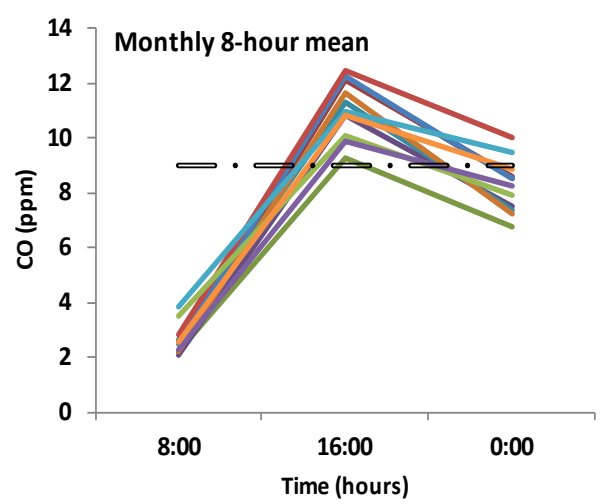

(a)

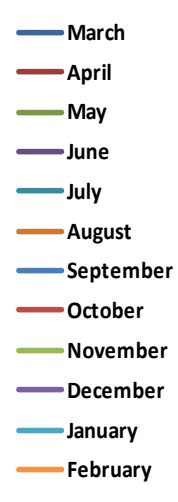

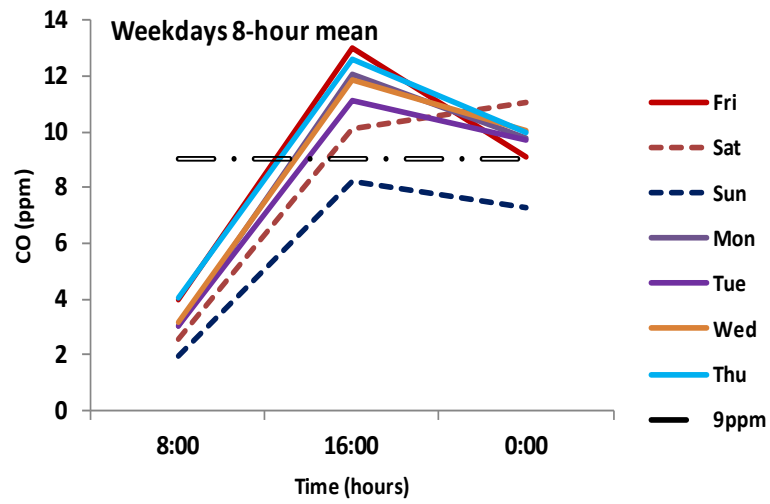

(b)

Figure 3. Mean diurnal variation of urban CO concentrations at the urban centre averaged over all (a) Monthly 8 hour mean (b) weekdays 8 hour mean from March, 2009-February, 2010.

Highest CO concentrations have been linked with motor vehicles emissions [9] [10].

\subsection{Diurnal and Seasonal Variations during Weekdays and Weekends}

The diurnal and seasonal variations of $1 \mathrm{~h}$ and $8 \mathrm{~h}$ mean concentrations of CO at our urban and rural sites in Akure during Weekdays, Saturdays and Sundays are shown in Figures 4-6 respectively. CO concentra- tions at the urban centre in Akure has been shown to exhibit distinct diurnal and day-of-week variations, with daytime mean 1 h values of 8 - 20 ppm and daytime mean 8 h values of 4 - 12 ppm, while the rural site exhibited a consistent similar cyclic diurnal pattern throughout the week, with daytime mean $1 \mathrm{~h}$ values of 2 - 10 ppm and daytime mean $8 \mathrm{~h}$ values of 4 - $8 \mathrm{ppm}$. Considering all the WHO time averages, the urban site CO concentration exceeds that of the rural which maintain a relatively low consistent cyclic diurnal pattern (Figure 2). 

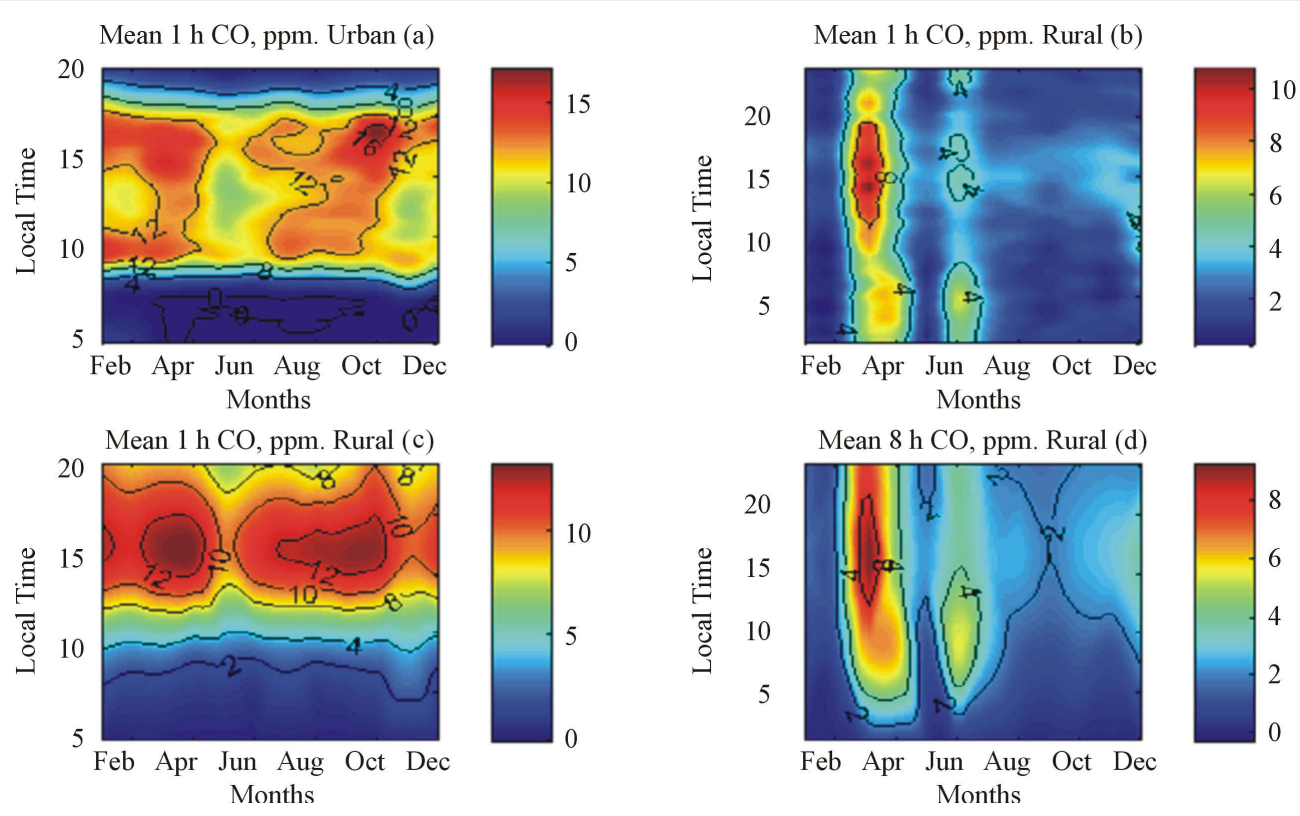

Figure 4. Diurnal/seasonal variations of $1 \mathrm{~h}$ and $8 \mathrm{~h}$ mean concentrations of $\mathrm{CO}$ at an urban and rural site during weekdays in Akure.
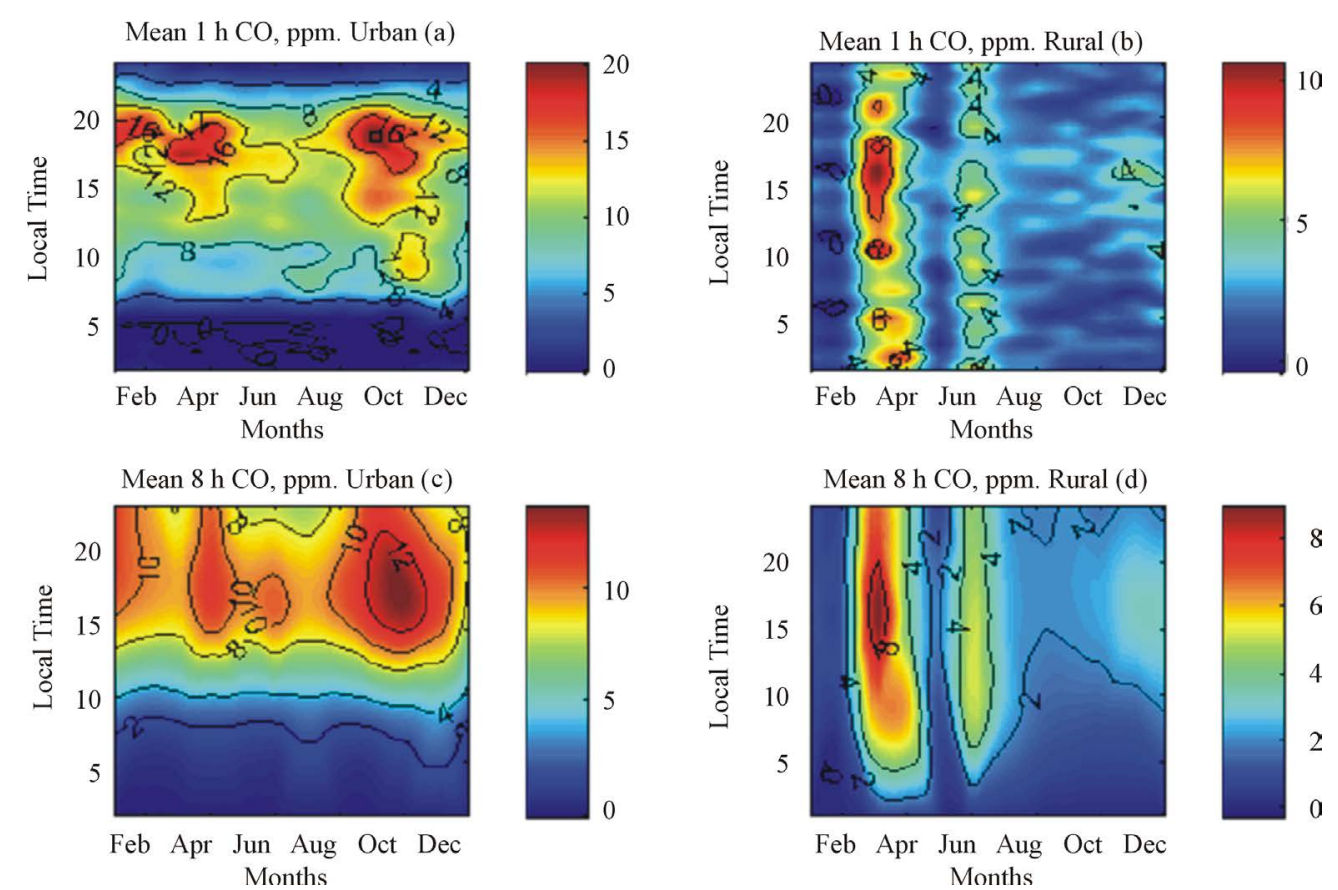

Figure 5. Diurnal/seasonal variations of $1 \mathrm{~h}$ and $8 \mathrm{~h}$ mean concentrations of $\mathrm{CO}$ at an urban and rural site on Saturdays in Akure.

\subsubsection{Weekdays Scenario}

In Figures 4(a) and (c), the diurnal and seasonal variations of $1 \mathrm{~h}$ and $8 \mathrm{~h}$ mean concentrations of $\mathrm{CO}$ at the urban site during Weekdays are clearly shown. Figure 4(a) shows a diurnal pattern with three peaks, two major during morning and evening rush hours, and a minor between 12:00 and 14:00 that may be associated with school runs to pick children from schools and lunch traffic. Friday is the most polluted of all week days particularly between 14:00 and 18:00 (Figure 3(b)), as earlier discussed to be associated with Muslim service, seeing that the central mosque is right in the city centre and also other social and weekend travel traffic activities. The 
zero concentrations recorded in the city centre between midnight and 05:00 in the mornings at all the days of the year, when there are little or no vehicles on the roads indicates that vehicular traffic is the main source of CO in the city centre. Result agrees with [5] identifying motor vehicle emission as one of the main sources of atmospheric pollution in the urban environment. Figure 4(a) further showed that the seasonal CO diurnal cycle during the daytime in the urban centre is greatly influenced by local meteorology, with highs in March and October and lows in May and November. Akure is a low wind area, with mean annual $10 \mathrm{~m}$ wind speed of $<2 \mathrm{~m} / \mathrm{s}$ and October records the lowest monthly wind speed, this may explain the observed higher concentration around 18:00 for both $1 \mathrm{~h}$ and $8 \mathrm{~h}$ mean concentrations in October (Figures 4(a) and (c) respectively). Although the impact of meteorology on the diurnal and seasonal variations still requires further investigations. WHO recommendations were not exceeded for $15 \mathrm{~min}, 30 \mathrm{~min}$ and $1 \mathrm{~h}$ averages; however the $8 \mathrm{~h}$ recommendation (9 ppm) were consistently exceeded between 13:00 to 20:00, except in May and November in Figure 4(c). The CO diurnal cycle observed here is different from observations in Burkina-Faso where two peaks during morning and evening rush hours have been reported [21]. They also reported that the average $8 \mathrm{~h}$ urban background CO concentrations never exceeded WHO recommendations for maximum $8 \mathrm{~h}$ exposure during their measurement campaigns.

Similar investigation was made to ascertain the scenario at the rural site during the weekdays, and the observed diurnal and seasonal variations of $1 \mathrm{~h}$ and $8 \mathrm{~h}$ mean concentrations of $\mathrm{CO}$ at the rural site is presented Figures 4(b) and (d). They both shows a diurnal pattern with a single peak between 12:00 and 16:00 associated with time of maximum insolation and atmospheric instability in all months of the year except in June. The highest concentrations were also observed in March and correspond with the peak of dry season with prevalent bush burning and forest fires. The rural farmers usually engage in these burning activities during their prospective farmland preparation towards the expected rains from April. This suggests that fires as a result of bush burning practices are the major source of $\mathrm{CO}$ at the rural site. However, rural background $\mathrm{CO}$ concentrations never exceeded WHO recommendations for maximum set time criteria exposure during the whole year.

\subsubsection{Saturdays Scenario}

Figure 5(a) and (c) show the diurnal and seasonal variations of $1 \mathrm{~h}$ and $8 \mathrm{~h}$ mean concentrations of $\mathrm{CO}$ at the urban site on Saturdays. Figure 5(a) further support that vehicular traffic is the main source of CO in the city centre as zero concentrations are recorded between midnight and 05:00 in the mornings similar to weekdays. However Saturday evenings have distinct evening peaks (18:00 - 20:00) associated with merry makers and party traffic, with highs in March and October for both $1 \mathrm{~h}$ and $8 \mathrm{~h}$ mean concentrations. WHO recommendations were not exceeded for $1 \mathrm{~h}$ averages; however the $8 \mathrm{~h}$ recommendation $(9 \mathrm{ppm})$ was consistently exceeded between 10:00 to 20:00 throughout the year. The behaviour at the rural site did not differ from observations during weekdays (Figures 5(b) and (d)).

\subsubsection{Sundays Scenario}

Figure 6(a) and (c) show the diurnal and seasonal variations of $1 \mathrm{~h}$ and $8 \mathrm{~h}$ mean concentrations of $\mathrm{CO}$ at the urban site on Sundays. Figure 6(a) show that Sundays have the lowest CO concentrations during the daytime with triple peaks at 7:00,13:00 and 19:00, corresponding to traffic related to going and return from Sunday church services. While that at 19:00 is related to evening outing activities. Apart from these, the pattern is similar to that observed on Saturdays with regards to seasonal variability and exceedance of WHO recommendations for $1 \mathrm{~h}$ and $8 \mathrm{~h}$ mean. The behaviour at the rural site did not differ from observations during weekdays (Figures 6(b) and (d)).

\section{Conclusion}

This study has revealed the air quality status of the Akure in terms of the carbon monoxide (CO) concentration levels at urban and rural scale, and also assessed the status with respect to the World Health Organisation (WHO) standard health-based guidelines on CO pollution. It is clearly shown that atmospheric contents of carbon monoxide concentrations at the urban site exceed that of the rural site for all the WHO time criteria. The CO concentrations at the urban centre in Akure exhibited distinct diurnal variations with two main peak periods, while the rural site exhibited a consistent similar cyclic diurnal pattern. Results further reveal the characteristic diurnal and seasonal variations of $1 \mathrm{~h}$ and $8 \mathrm{~h}$ mean CO concentrations at the urban and rural sites in Akure during Weekdays, Saturdays and Sundays respectively. CO concentrations only exceeded the WHO 8-hour average 

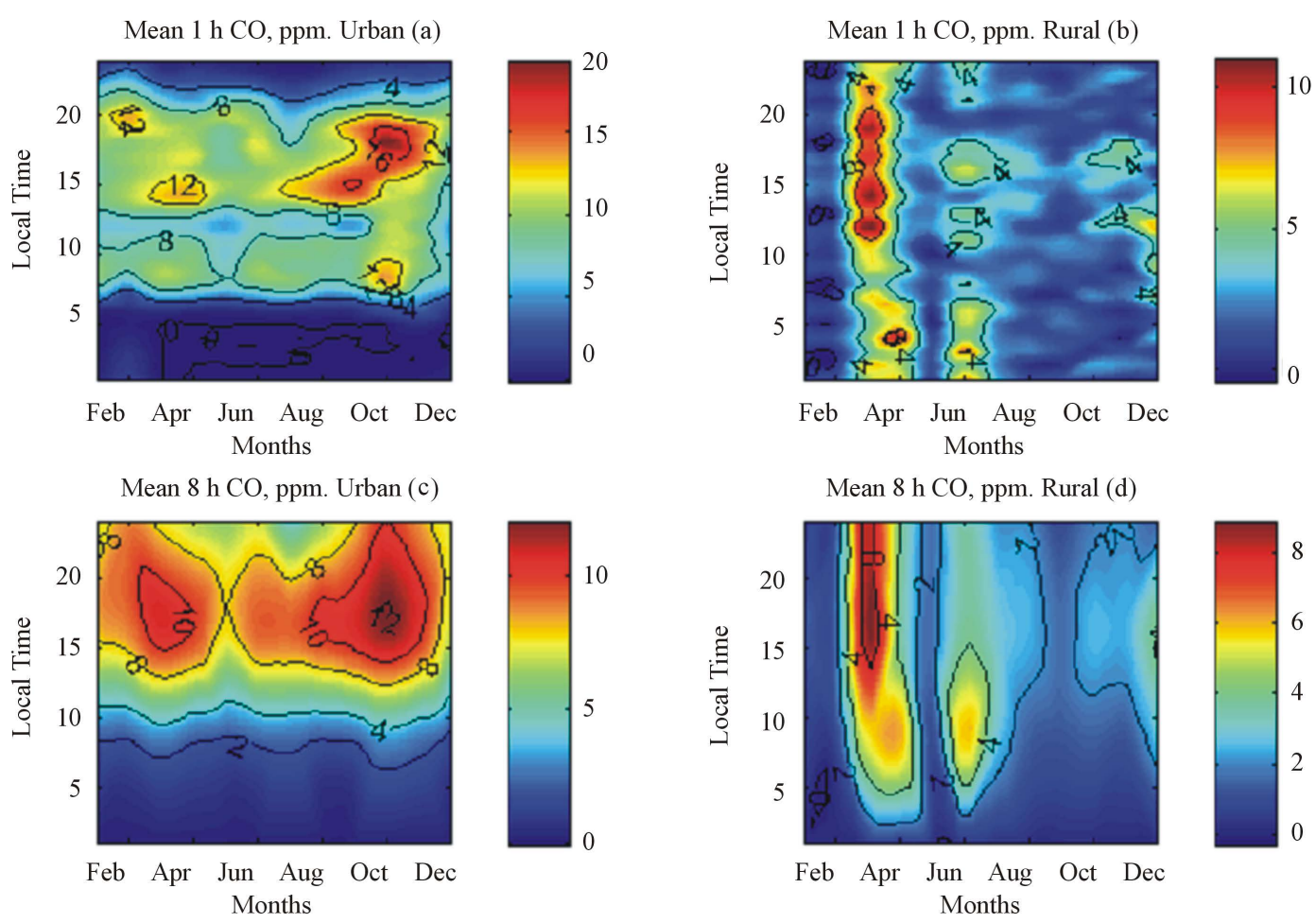

Figure 6. Diurnal/seasonal variations of $1 \mathrm{~h}$ and $8 \mathrm{~h}$ mean concentrations of CO at an urban and rural site on Sundays in Akure.

recommendation at the city centre throughout the week during daytime. Results from this study identified the major cause of $\mathrm{CO}$ concentration in the city to be vehicular as there is a consistent increase of the air pollutant from 08:00 to 16:00 during the weekdays that are associated with "school runs and rush hours (resumption and closing) related to office workers" and also through the midnight hours on days linked with social events, particularly Saturdays. The traditional African social life has also been identified to append its signature on the CO concentration level observed in the Saturday's pattern. This air quality degradation identified as a major problem that gradually follows rapid urbanisation will in no doubt have adverse effects on human health due to increased emissions from traffic. This is the first pilot measurement of $\mathrm{CO}$ in Akure and further studies are required to relate traffic volume and meteorology to the observed variations for the adequate assessment. However, findings presented in this study could serve as a valuable tool in reducing urban environmental health risks connected to $\mathrm{CO}$ pollution, if used in planning, as well as development of strategies for air pollution mitigation in Akure.

\section{References}

[1] UN Development Programme Human Development Report (2010) The Real Wealth of Nations: Pathways to Human Development. United Nations Development Programme.

[2] UN Habitat (2010) State of African Cities 2010, Governance, Inequalities and Urban Land Markets. UNEP, Nairobi.

[3] Baumbach, G., Vogt, U., Hein, K.R.G., Oluwole, A.F., Ogunsola, O.J. and Olaniyi, H.B. (1995) Air Pollution in a Large Tropical City with a High Traffic Density-Results of Measurements in Lagos. Nigeria. The Science of the Total Environment, 169, 25-31. http://dx.doi.org/10.1016/0048-9697(95)04629-F

[4] Gwilliam, K. (2003) Urban Transport in Developing Countries. Transport Reviews, 23, 197-216. http://dx.doi.org/10.1080/01441640309893

[5] Klidonas, Y. (1993) The Quality of the Atmosphere in Athens. Science of the Total Environment, 129, 83-94. http://dx.doi.org/10.1016/0048-9697(93)90163-Z

[6] CAI-SSA (2006) Promoting Cleaner Vehicles. Regional Conference on Better Air Quality in Sub-Saharan African Cities, Nairobi, 25-26 July 2006.

[7] Arku, R.E., Vallarino, J., Dionisio, K.L., Willis, R., Choi, H., Wilson, J.G., Hemphill, C., Agyei-Mensah, S., Spengler, J.D. and Ezzati, M. (2008) Characterizing Air Pollution in Two Low-Income Neighborhoods in Accra, Ghana. Science 
of the Total Environment, 402, 217-231. http://dx.doi.org/10.1016/j.scitotenv.2008.04.042

[8] Sathitkunarat, S., Wongwises, P., Pan-Aram, R. and Zhang, M. (2006) Carbon Monoxide Emission and Concentration Models for ChiangMai Urban Area. Advances in Atmospheric Sciences, 23, 901-908. http://dx.doi.org/10.1007/s00376-006-0901-9

[9] Liu, J.J., Chan, C.C., and Jeng, F.T. (1996) Predicting Personal Exposure Levels to Carbon Monoxide (CO) in Taipei, Based on Actual CO Measurements in Microenvironments and a Monte Carlo Simulation Method. Atmospheric Environment, 28, 2361-2368. http://dx.doi.org/10.1016/1352-2310(94)90490-1

[10] Chaloulakou, A., Duci, A. and Spyrellis, N. (2002) Exposure to Carbon Monoxide in Enclosed Multi Level Parking Garages in Central Athens Urban Area. Indoor Built Environment, 11, 191-201. http://dx.doi.org/10.1177/1420326X0201100403

[11] World Health Organisation (2004) Environmental Health Criteria. 2nd Edition, Vol. 213, Carbon Monoxide.

[12] Forster, P., Ramaswamy, V., Artaxo, P., Berntsen, T. and Betts, R. (2007) Changes in Atmospheric Constituents and in Radiative Forcing, in Climate Change 2007: The Physical Science Basis. Cambridge University Press, New York, 131-215.

[13] Georgoulis, L.B., Hänninen, O., Samoli, E., Katsouyanni, K., Künzli, N. and Polanska, L. (2002) Personal Carbon Monoxide Exposure in Five European Cities and Its Determinants. Atmospheric Environment, 36, 963-974. http://dx.doi.org/10.1016/S1352-2310(01)00473-3

[14] di Marco, G.S., Kephalopoulos, S., Ruuskanene, J. and Jantunene, M. (2005) Personal Carbon Monoxide Exposure in Helsinki, Finland. Atmospheric Environment, 39, 2697-2707. http://dx.doi.org/10.1016/j.atmosenv.2004.07.039

[15] Boddy, J.W.D., Smalley, R.J., Dixon, N.S., Tate, J.E. and Tomlin, A.S. (2005) The Spatial Variability in Concentrations of a Traffic-Related Pollutant in Two Street Canyons in York, UK, Part II. The Influence of Traffic Characteristics. Atmospheric Environment, 39, 3163-3176. http://dx.doi.org/10.1016/j.atmosenv.2005.01.044

[16] Zhao, L., Wang, X., He, Q., Wang, H., Sheng, G. and Chan, L.Y. (2004) Exposure to Hazardous Volatile Organic Compounds, PM10 and CO While Walking along Street in Urban Guangzhou, China. Atmospheric Environment, 38, 61776184. http://dx.doi.org/10.1016/j.atmosenv.2004.07.025

[17] Vardoulakis, S., Gonzalez-Flesca, N. and Fisher, B.E.A. (2002) Assessment of Traffic-Related Air Pollution in Two Street Canyons in Paris: Implications of Exposure Studies. Atmospheric Environment, 36, 1025-1039. http://dx.doi.org/10.1016/S1352-2310(01)00288-6

[18] Beauchamp, J., Wisthaler, A., Grabmer, W., Neuner, C., Weber, A. and Hansel, A. (2004) Short-Term Measurements of $\mathrm{CO}, \mathrm{NO} \mathrm{NO}_{2}$, Organic Compounds and $\mathrm{PM}_{10}$ at Motorway Location in an Austrian Valley. Atmospheric Environment, 38, 2511-2522. http://dx.doi.org/10.1016/j.atmosenv.2004.01.032

[19] Chan, A.T. (2003) Commuter Exposure and Indoor-Outdoor Relationships of Carbon Oxides in Buses in Hong Kong. Atmospheric Environment, 37, 23809-3815. http://dx.doi.org/10.1016/S1352-2310(03)00465-5

[20] Han, X. and Naeher, L.P. (2006) A Review of Traffic-Related Air Pollution Exposure Assessment Studies in the Developing World. Environment International, 32, 106-120. http://dx.doi.org/10.1016/j.envint.2005.05.020

[21] Linden, L., Thorsson, S. and Eliasson, I. (2008) Carbon Monoxide in Ougadougou, Burkina Faso-A Comparison between Urban Background, Roadside and In-Traffic Measurements. Water, Air, Soil Pollution, 188, 345-353. http://dx.doi.org/10.1007/s11270-007-9538-2

[22] Balogun, I.A., Adeyewa, Z.D., Balogun, A.A. and Morakinyo, T.E. (2011) Analysis of Urban Expansion and Land Use Changes in Akure, Nigeria, Using Remote Sensing and GIS Techniques. Journal of Geography and Regional Planning, 4, 533-541.

[23] Balogun, I.A., Balogun, A.A. and Adeyewa, Z.D. (2012) Observed Urban Heat Island Characteristics in Akure, Nigeria. African Journal of Environmental Science and Technology, 4, 1-8.

[24] Millennium Cities Initiative Report (2007) http://www.ebookbrowse.com/mci-project-description-2007-02-21-pdf-d468100392

[25] Stewart, I.D. and Oke, T.R. (2010) Thermal Differentiation of Local Climate Zones Using Temperature Observations from Urban and Rural Field Sites. 9th Symposium on Urban Environment, Keystone, Colorado, 2010. 